\title{
«Some records are impossible to break with a natural body»... Ja und?
}

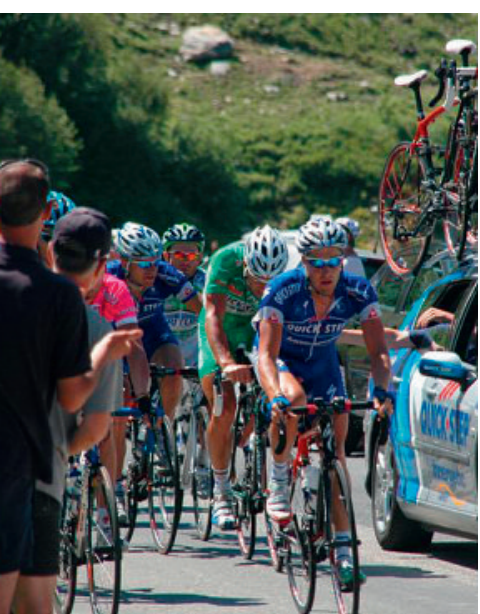

Höchstleistung um jeden Preis? Welchen Preis? Wofür?

1 Missa JN. Sport, enhancement and the inefficacy of antidoping policy. Bioethica Forum. 2011;4(1):14-6.

2 Kayser B, Mauron A, Miah A. Current anti-doping policy: a critical appraisal. BMC Medical Ethics. 2007;8:2.

3 Martin J. Dopage: rien de changé depuis Rome et «panem et circenses»? Schweiz Ärztezeitung. 2006;87(41):1791-2.

4 Martin J. Ethique sportive. Schweiz Ärztezeitung. 2010;91(23):920-1.
In der jüngsten Ausgabe der Zeitschrift «Bioethica Forum» der Schweizerischen Gesellschaft für Biomedizinische Ethik ist mir der Artikel des belgischen Bioethikers Jean-Noël Missa aufgefallen [1]. Zunächst durch den Satz, den ich als Titel gewählt habe. Müssen wir sportliche Rekorde immer wieder brechen? Was würden wir verlieren, wenn jeweils die Besten des Moments gekürt würden, ohne die Ergebnisse zwangsläufig mit Olympischen Spielen zu vergleichen? Würde man damit an den fatalen Trieb der Menschen rühren, immer noch schneller und noch schneller sein zu wollen? Doch in Zeiten, in denen uns Fukushima und anderes - Klimawandel und eine Wirtschaft, in der die Kluft zwischen Arm und Reich immer grösser statt kleiner wird - erneut vor essentielle Fragen über unsere Fortschrittsauffassung stellen, ist es dringend geboten, diesen Trieb einzudämmen, ihm entgegenzuwirken.

Missa erachtet die aktuelle Anti-Doping-Praktik als fragwürdig. Besonders aufmerksam machen Aussagen wie Doping sei eine der essentiellen Komponenten des Leistungssports und die (leistungssteigernde) Biomedizin-Technologie bilde das Herz des Elitesports. Missa stellt überdies die Frage, ob es nicht paradox anmute, ein Verhalten (nämlich die Verwendung künstlicher Hilfsmittel) zu verbieten, das den Dreh- und Angelpunkt des Leistungssports bilde. Hat er das substantielle Charakteristikum des Sports damit wirklich treffend beschrieben?

Jeder hat das Recht, sich selbst in Gefahr zu bringen, indem er z. B. Klettersport betreibt, Autorennen fährt oder einfach nur raucht. Wenn also viele Athleten verbotene Substanzen einnehmen, würde man gegen ihren Willen ihre Freiheit beschneiden? Im Sinne einer an möglichen Folgen ausgerichteten Ethik spreche ich mich weiterhin für die Bekämpfung des Dopings aus, denn die Schäden durch eine liberale Praxis, die zwar «medizinisch überwacht», aber larga manu betrieben würde, wären schwerwiegender. Zwar kann man behaupten, der-zeit seien Sportfunktionäre und Athleten gezwungen, heimlich «höher, schneller, weiter» zu kommen. Sicher ist aber, dass auf das Gesamtkollektiv der Sportler betrachtet derzeit weniger potentiell toxische Substanzen eingenommen werden, als bei einer Liberalisierung.

Es ist eine Illusion zu glauben, erlaubtes Doping unter medizinischer Kontrolle sei weniger pathogen. Dazu muss man an die Unfehlbarkeit des Menschen, der Ärzte und der Verfahren glauben. Wir wissen alle, dass jedes System die Kreativität des Menschen anstachelt, damit er es drehen oder an seine Grenzen trei- ben kann - Kollegen kritisieren das Gutmenschentum bzw. die Weltfremdheit der Anti-Doping-Verfechter, begehen aber denselben Fehler, wenn Sie glauben, alles wäre «in Ordnung», solange ein Spezialist den Athleten überwacht. Wenn aber dann Dutzende von Sportlern den ärztlich verordneten Substanzen zum Opfer fallen, wird es ein grosses Geschrei geben und man wird Kontrollen (z.B. der Kompetenzen der Ärzte - denn es gibt auch schlechte) und Beschränkungen fordern (um kurz- oder langfristig zu gefährliche Mittel auszuschliessen) usw. Was würde sich dann also am aktuellen Paradigma ändern?

Man muss der Tatsache Rechnung tragen, dass der Leistungssport weltweit ein Millionenpublikum begeistert. Der Sport hat darüber hinaus eine Beispielfunktion, was die Verantwortlichen im Sport und im gesellschaftlichen Leben mit Nachdruck betonen. Ich finde es sonderbar, wie Missa für eine liberale Dopingpraxis mit der Behauptung zu argumentieren, durch Doping und Einsatz der besten Wissenschaftler auf diesem Gebiet Vorteile zu erreichen - sportliche und finazielle - , entspreche durchaus dem Gedanken des Wettbewerbs [2].

Auf dem Gebiet der allgemeinen Drogenpolitik hat mich die Erfahrung gelehrt, Doktrinen abzulehnen, die auf Strafen und Postulaten der «Tugendhaftigkeit» basieren, da sie, indem sie die Abstinenz als einzig statthaftes Ziel darstellen, bei geschwächten Personen grossen Schaden anrichten können. Ich habe mich für unterstützende Massnahmen für Drogenabhängige, die vom Leben «Gebrochenen», eingesetzt; dazu gehört auch die Gabe von Betäubungsmitteln (z. B. Methadon). Diese Haltung führt aber nicht zur Anerkennung von Doping im Sport. Der Hochleistungssport ist eine besondere Subgruppe der Gesellschaft. Vertreter der Gesundheitsberufe, die dem Grundsatz Primum non nocere verpflichtet sind, haben nicht die Aufgabe, a priori gesunden Menschen gefährliche Substanzen zu verabreichen auf die Gefahr hin, auch aus ihnen vom Leben Gebrochene zu machen, nicht zuletzt wegen der Spätschäden.

Und schliesslich ist niemand gezwungen, in den Wettkampf einzutreten, wenn ihm die Regeln nicht passen. Die Doping-Debatte ist komplex, aber das Modell «anything goes» ist entschieden zu schön, um wahr zu sein. Die Gesellschaft ist gut beraten, zu bedenken, dass Freiheit nur wertvoll ist, wenn ihr auch Grenzen gesetzt werden [3, 4]. und der Nationalen Ethikkommission 